\title{
Uncertainty and the Welfare Economics of Medical Care: An Austrian Rebuttal-Part 3
}

\author{
Gilbert Berdine MD
}

\begin{abstract}
Part 3 concludes the rebuttal to the argument that health care is special and that markets cannot properly distribute health care. Part 1 was a general discussion of the argument made by Kenneth Arrow. Part 2 focused on the problem of asymmetric information in health care. Part 3 considers the argument that health care is a human right and concludes that it is not. All aspects of health care are composed of scarce resources which cannot be supplied in unlimited quantity upon demand. The belief that health care is a right leads to subsidies which distort the price structure in health care. Rising costs and increasing unaffordability are the inevitable consequences of these subsidies. A health care right becomes an insatiable demand; spending on other aspects of life is crowded out leading to a declining standard of living for those paying for health care. The assumption that health care is a right causes competitive innovation to be replaced by rent seeking behavior particularly the grant of subsidies for very expensive treatments with low benefits.
\end{abstract}

Keywords: health care economics, health care uncertainty, health care right, health care costs, health care market failure

Part $1^{1}$ of this series discussed general arguments advanced by Kenneth Arrow about health care. Part $2^{2}$ of this series discussed the specific concept of information asymmetry. In Part 3, I will discuss the argument that health care is a human right and cannot be treated as an economic commodity.

Is health care a human right? Some people believe that answer is affirmative. Pope Francis said, "Health is not a consumer good, but rather a universal right, and therefore access to health care services cannot be a privilege." ${ }^{3}$ Article 25 (1) of the Universal Declaration of Human Rights includes, "Everyone has the right to a standard of living adequate for the

Corresponding author: Gilbert Berdine Contact Information: gilbert.berdine@ttuhsc.edu DOI: $10.12746 /$ swrccc.v5i19.388 health and well-being of himself and of his family, including food, clothing, housing and medical care and necessary social services, ..."4 The World Health Organization, in its health and human rights fact sheet, states, "The right to health includes access to timely, acceptable, and affordable health care of appropriate quality." ${ }^{5}$ The official position of Physicians for a National Health Program, an organization of over 17,000 physicians, states, "Access to comprehensive health care is a human right. It is the responsibility of society, through its government, to assure this right." 6

The answer is no and the economic argument is clear. Health care cannot possibly be a human right. A right is something that must be supplied in unlimited quantity upon demand at a price of zero. This is impossible for any scarce resource. It would be silly to believe that health care is not scarce. Supplies necessary for health care are clearly scarce. Equipment necessary for health care are clearly scarce. Even the most basic aspect of health care which is the physician 
taking a history and examining a patient requires time which is clearly scarce. The health care profession even has a word that recognizes the scarcity: triage. Triage is the prioritizing of care to those with greatest need when all patient needs cannot be provided, which is all of the time. We all practice triage whether we want to admit it or not.

Let's contrast health care with free speech. A newspaper has the right to freely state its opinions, because it does not cost the government any resources to allow the newspaper to do so. An individual does not have the right, however, to have an opinion printed in the newspaper, because the publication requires scarce resources and the newspaper can decide how those resources should be used.

Even Kenneth Arrow admitted that health care was a scarce resource.

"The belief that the ethics of medicine demands treatment independent of the patient's ability to pay is strongly ingrained. Of course, this expectation amounts to ignoring the scarcity of medical resources; one has only to have been poor to realize the error."7

The Western world pretends that health care is a right or entitlement - health care available to people with money is made available to everyone by the use of government subsidies. The subsidies set in motion an inexorable chain of events that shatter the illusion of a right. The subsidy has the predictable consequence of increasing demand. This directly increases the cost of healthcare. Even if the subsidies are initially limited to catastrophes, there will be inevitable calls to expand the range of services covered by the subsidies and expand the number of people eligible for the subsidies. It is no accident that the providers of healthcare favor the expansion of the subsidies. The cost of pretending that health care is a right grows exponentially. Eventually the rising costs lead to restrictions on eligibility which is contradictory to a right.

It does not matter how the cost of health care in the U.S. is measured. One can measure it in total health care $\operatorname{cost}^{8}$, one can adjust for population (as I have done in Figure 1), one can adjust for the Consumer Price Index, or one can adjust for economic output;

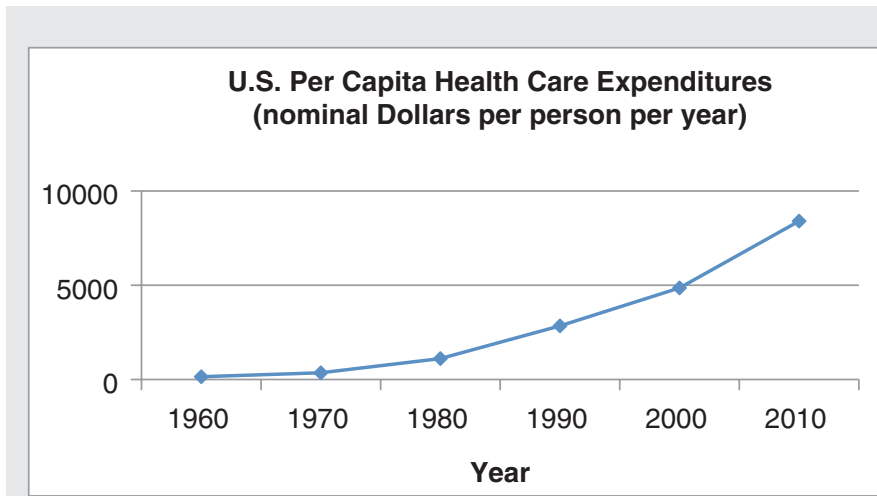

Figure 1.

the result is exponential growth. Exponential growth will continue until whatever feeds the growth is exhausted. In the case of health care the subsidies are feeding the growth.

Eventually the growing costs lead to cost control, but cost control is incompatible with a right. The form of cost control used in the West is restricted access even though it is access that is claimed to be a right. Restricted access can take many forms. One form is a bureaucracy that decides eligibility for care. The bureaucracy never explains how its function is compatible with a right. Another form of restricted access is a long queue. In extreme cases, people die waiting for their care. Government health care programs measure output by how much money is spent and how many people are enrolled rather than how many patients receive actual care. Innovation to provide more and better care at lower prices is replaced by rent seeking to secure broader eligibility for ever increasing subsidies that offset ever increasing prices. Over time, fewer and fewer people can afford to pay for health care without the benefit of a subsidy.

Compare the cost of health care with the cost of a competitive commodity like hard drive storage.

Figure 2 shows a declining price over time. Note the log scale for price. What was a luxury in 1980 is dirt cheap today. This declining price is the consequence of competitive innovation. Data storage is cheap because we have no government regulations defining what storage is, what materials it must be 


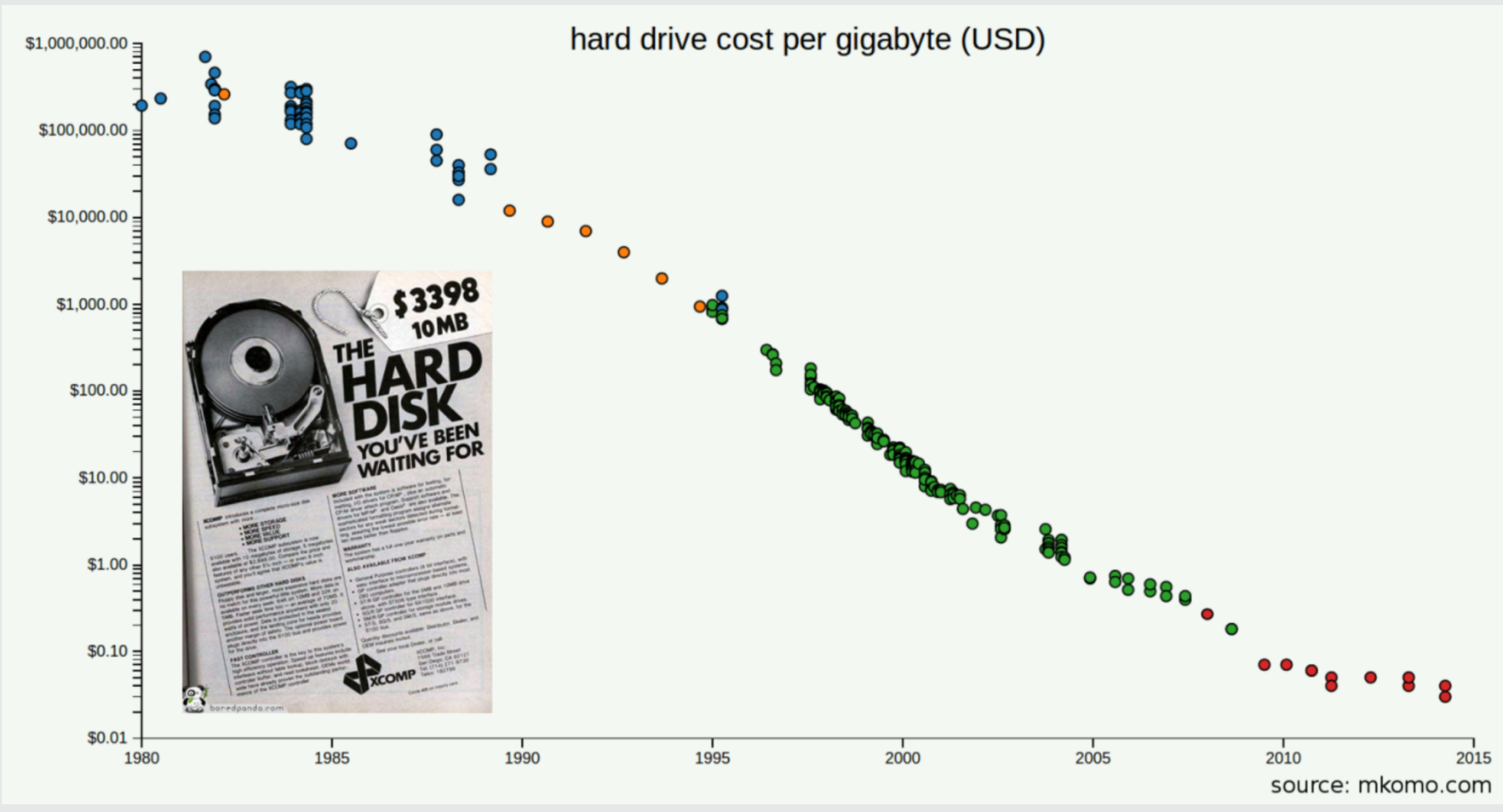

Figure 2. ${ }^{9}$

made from, who may manufacture it, who may sell it, and countless other restrictions on the trade of storage between suppliers and consumers. There is no FDA for hard drives that require manufacturers to perform expensive studies that demonstrate efficacy or safety. Yet, somehow, hard drives seem to work just fine and customers are satisfied.

The fantasy of a right to health care has many casualties. The production of health care means that other things are not produced. This was described by the French economist Frederic Bastiat as, "That Which is Not Seen." 10 The choices are not between some person getting health care and that same person not getting health care. The choices are between some person getting health care and everyone else getting some other good. Markets set limits on how much will be sacrificed in order to help those in need. Rights have no such boundaries. Eventually standards of living must decrease in order to feed Figure 1. In the United States, eventually has already occurred.
Figure 3 illustrates the death of the American Dream. The American Dream is that each generation enjoys a better standard of living than earlier generations. Since 2000, this is no longer true. This decline in standard of living spans two presidents, one from each major party. While the costs of health care are not the only reasons for Figure 3, they are a large part of the problem.

Another casualty of the so-called right to health care is moral hazard. Consider the end of life. The end of life is inevitable for each person, so this condition is not insurable. The only way to finance end of life care is savings accumulated earlier in life. Term life insurance, on the other hand, is a bet on whether someone dies within a finite time frame and can be actuarially sound. Whole life insurance is a bet that premiums invested will earn enough before death to pay a pre-defined death benefit; this can also be actuarially sound. Neither an open ended in time bet on death, nor an open ended death benefit would be actuarially sound. 


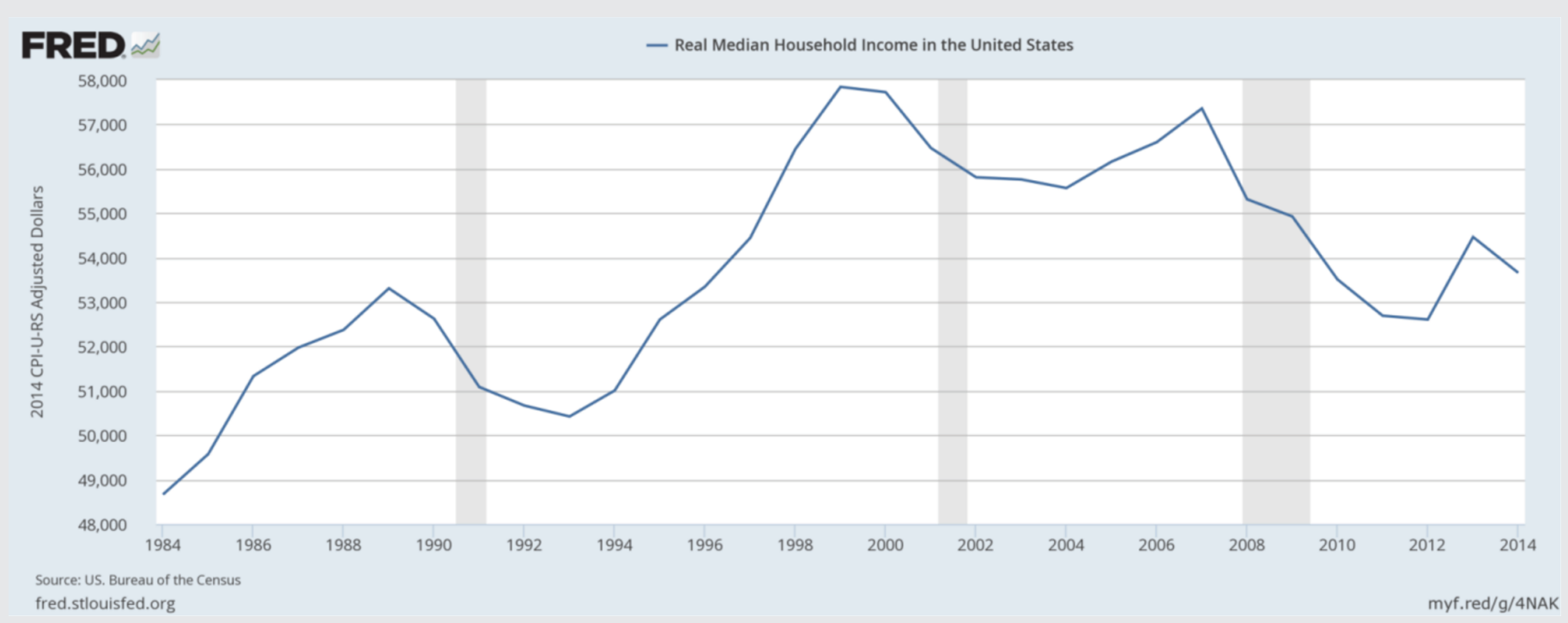

Figure 3. ${ }^{11}$

What happens under a delusion that health care is a right? In 2009, it was estimated that Medicare paid $\$ 50$ billion on care for the last two months of life. ${ }^{12}$ A study on Medicare beneficiaries from 1992-1996 showed that the average expenditure per beneficiary during the last year of life was $\$ 37,581$ vs. $\$ 7,365$ during non-terminal years. ${ }^{13}$ That is a lot of money for little or no return. People would not spend money on futile measures to prolong life an insignificant amount if it were their own money. People would rather pass the money on to their heirs. Much of health care research is on how to spend ever increasing amounts for ever smaller - but statistically significant - returns at the end of life, and there is little interest in health maintenance that would cost much less and have greater impacts for more people. Competitive innovation that would decrease the cost of health care and improve the standard of living is replaced by rent seeking behavior to obtain government subsidies for the latest gimmick, gadget or medication irrespective of cost. Everyone seeks to spend more of someone else's money.

The final casualty of the so-called right to health care has been the doctor-patient relationship. When doctors are paid by their patients, there are no conflicts of interest; the doctor serves the patient who is paying the bill. When a doctor is paid by a hospital, an insurance company or a government agency, the doctor will inevitably put the interests of the payer before the interests of the patient. This conflict is well illustrated when government mandated measures on Length of Stay collide with patient desires to remain in the hospital. The modern notion of health insurance being attached to employment and covering uninsurable items such as health maintenance is another casualty of government interference with markets. In this case the government enacted wage and price controls during World War II and health insurance was allowed to be a benefit outside of the controls. Each government intervention with markets makes the economic situation worse than it was before.

In summary, I disagree with Kenneth Arrow on several points. Uncertainty is not unique to health care. Health care is not special either in economic terms, as Arrow contended, or as a human right, as others have claimed. The market is capable of handling uncertainty of demand (incidence) by insurance, but insurance must be limited to insurable conditions. The bulk of what is called health care is not emergency care for life threatening conditions 
that is insurable, but rather is health maintenance or treatment of expected situations which must be paid for out of pocket. The market handles uncertainty of outcome by brand recognition. The market handles asymmetric information by having experts sell valuable information. The market handles indigent care through charity. Government attempts to directly provide health care end up like the VA. "VA Scandal" gets $18,800,000$ hits on Google, has its own Wikipedia entry, and has been well documented by news organizations sympathetic to government health care. ${ }^{14}$ Government attempts to manipulate price discovery through subsidies are bankrupting the nation.

Article citation: Berdine G. Uncertainty and the welfare economics of medical care: an Austrian rebuttal-part 3. The Southwest Respiratory and Critical Care Chronicles 2017; 5(19): 25-29

From: Department of Internal Medicine, Texas Tech University Health Sciences Center, Lubbock, TX

Submitted: $2 / 20 / 2017$

Accepted: 4/8/2017

Reviewer: Robert P Murphy PhD

Conflicts of interest: none

\section{REFERENCES}

1. Berdine G. Uncertainty and the welfare economics of medical care: an Austrian rebuttal: part 1. 2016 2016;4:5.

2. Berdine G. Uncertainty and the welfare economics of medical care: an Austrian rebuttal Part 2. 2017 2017;5:5.
3. Pope Francis: health care is a 'universal right,' not a 'consumer good'. Catholic Culture. 2016, at https://www.catholicculture.org/news/headlines/index.cfm?storyid=28266

4. Universal Declaration of Human Rights. Amnesty International. http://www.amnestyusa.org/research/human-rightsbasics/universal-declaration-of-human-rights

5. Health and human rights. World Health Organization. 2015, http://www.who.int/mediacentre/factsheets/fs323/en/

6. Physicians for a National Health Program (PNHP) Biography. ProCon.org. 2010, http://healthcare.procon.org/view. source.php?sourceID $=009493$

7. Arrow KJ. Uncertainty and the welfare economics of medical care. 1963. Bull World Health Organ 2004;82:141-9.

8. CMS.gov Centers for Medicare and Medicaid Services. 2016, at https://www.cms.gov/research-statistics-data-andsystems/statistics-trends-and-reports/nationalhealthexpenddata/nationalhealthaccountshistorical.html.)

9. The Great Stock Market Swindle. ZeroHedge. 2017, at http:// www.zerohedge.com/news/2016-08-13/great-stock-marketswindle.)

10. Bastiat F. That Which is Seen, and That Which is Not Seen. In: Rideau. F-R, ed.

11. Real Median Household Income in the United States. Federal Reserve Bank of St.Louis. at https://fred.stlouisfed.org/ series/MEHOINUSA672N.)

12. The Cost of Dying. at http://www.cbsnews.com/news/ the-cost-of-dying/.)

13. Hoover DR, Crystal S, Kumar R, Sambamoorthi U, Cantor JC. Medical expenditures during the last year of life: findings from the 1992-1996 Medicare current beneficiary survey. Health Serv Res 2002;37:1625-42.

14. Audit: More than 120,000 veterans waiting or never got care. CNN. 2014, at http://www.cnn.com/2014/06/09/politics/ va-audit/.) 